Editorial

\title{
Old-Age Exclusion: Active Ageing, Ageism and Agency
}

\author{
Wouter De Tavernier ${ }^{1, *}$ and Marja Aartsen ${ }^{2}$ \\ ${ }^{1}$ Center for Social and Cultural Psychology, KU Leuven, 3000 Leuven, Belgium; E-Mail: wouter.detavernier@kuleuven.be \\ 2 NOVA-Norwegian Social Research, OsloMet-Oslo Metropolitan University, 0130 Oslo, Norway; \\ E-Mail: marja.aartsen@oslomet.no \\ * Corresponding author
}

Submitted: 19 July 2019 | Published: 29 July 2019

\begin{abstract}
This editorial serves a double purpose. It introduces the articles and commentary comprising this thematic issue on old-age exclusion, and simultaneously aims to make a concise contribution to the discussion on the relation between agency of older people and old-age exclusion. While indeed it is clear that limitations of agency due to a lack of resources in old age or age discrimination lead to exclusion of older people, the relationship between reduced agency and exclusion is less clear in the case of internalized age norms. It ends with a plea for surveys studying older populations to pay more attention to older people's identities and life goals, opinions and reasons for action.
\end{abstract}

\section{Keywords}

active ageing; ageism; agency; old-age exclusion; well-being

\section{Issue}

This editorial is part of the issue "Old-Age Exclusion", edited by Wouter De Tavernier (KU Leuven, Belgium) and Marja Aartsen (OsloMet-Oslo Metropolitan University, Norway).

(C) 2019 by the authors; licensee Cogitatio (Lisbon, Portugal). This article is licensed under a Creative Commons Attribution 4.0 International License (CC BY).

Over the last decades, the idea of active ageing spread around Europe (Foster \& Walker, 2015). Faced by challenges posed by population ageing, international organizations such as the United Nations (2002), the World Health Organization (2002) and the European Commission (2018), promote active ageing as a way to keep older people healthy and utilize their productive capacity. Even though the concept is primarily used to promote older individuals as a productive factor, it also has a broader understanding, one in which older individuals are conceived of as full members of society (Boudiny, 2013; Foster \& Walker, 2015; Walker, 2008). This conception reflects Marshall's (1950) understanding of citizenship in which full citizenship is only reached when individuals actively participate in economic, social and political life.

Many older people are excluded from participating in society due to various barriers. As Walsh, Scharf and Keating (2017) point out, exclusion can be conceptualized as a lack of agency, with structural barriers limiting options for participation for older individuals. When ap- proaching exclusion as a lack of agency, the primary target of attempts to boost inclusion of older people should be the removal of any barriers in society that limit options for older people. Failure to do so may have negative consequences. The article by Precupetu, Aartsen and Vasile (2019) in this issue illustrates the detrimental effects of exclusion on the well-being of older individuals. Following the aspects of old-age exclusion identified by Walsh et al. (2017), Precupetu et al. (2019) examine associations between exclusion from financial resources, services, social relations and the community and well-being. The article indicates not only that well-being is severely negatively impacted by these forms of exclusion, but also that they are an important contributor to the lower levels of well-being of older individuals in Romania compared to younger generations. In particular, the lack of financial resources has a strong impact, illustrating the need for economic interventions to boost well-being of older Romanians.

It can moreover be argued that the individual's economic capital is a key determinant of other forms of ex- 
clusion in later life. Jensen, Kongshøj and De Tavernier (2018), for instance, find that economic hardship reduces older individuals' active involvement in society, while De Tavernier and Draulans (2019) argue that it may hamper access to formal care even if this care is available at low cost. Given the tight link between pensions and the life course (Peeters \& De Tavernier, 2015), planning ahead for retirement is essential to avoid a sudden drop in standard of living at retirement, particularly in countries with limited retirement provisions. In this issue, Preston (2019) presents a literature review of the factors inhibiting planning. The article illustrates how economic but also social exclusion in middle age bears the seeds for exclusion in later life by limiting individuals' capacities to plan for retirement.

Ageism (Butler, 1969) or age discrimination, still widespread in European societies (Ayalon \& Tesch-Römer, 2017, 2018), also contributes to the exclusion of older individuals in society (Walsh et al., 2017). In their commentary, De Tavernier, Naegele and Hess (2019) critically assess the assumption that ageism is a product of modernization in the light of recent socio-economic developments. Whereas ageism is often analyzed from the perspective of individuals limiting others' possibilities and therefore their agency, the psychological literature has also shown that older individuals internalize ageist ideas (Swift, Abrams, Lamont, \& Drury, 2017). Van der Horst (2019) analyses the relationship between ageism and retirement preferences in this issue. While several articles have identified formal and informal age norms as external drivers of retirement preferences (e.g., De Tavernier \& Roots, 2015; Hess, 2016), this article analyses whether internalized ageism, conceptualized as agerelated self-perceptions, leads to a preference for earlier retirement. This shows the limits of conceptualizing exclusion in terms of agency: structure goes well beyond external limitations to individuals' choice options, is being internalized and shapes individuals' very preferences (De Tavernier, 2016). The individual would not experience the internalized norms as limiting their options and would perceive following them as exercising their free will.

The role of goals and preferences is a central aspect of the ethical analysis of active ageing by Pfaller and Schweda (2019). In their article, they critically assess the active ageing discourse as a denial of agency because it assumes preferences for activity and denies older individuals to set their own goals. They explore the meaning of "the good life" in old age and advocate a paradigmatic shift in the politics surrounding ageing away from the productivity-centered interpretation of active ageing, towards one rooted in the capability approach. Only that way, they argue, politics can improve the situation of older people in society without at the same time enforcing norms about how older people should be living their lives. Inclusion, then, is to have the capacity to pursue one's own goals-that is, to have agency.

In the light of the articles published in this thematic issue, we should ask ourselves as a research community if we really have the tools necessary to assess exclusion of older individuals, particularly in quantitative research. For all their benefits, most surveys designed to understand the world older people live in include very little information on what older individuals actually want, how they see themselves and their role in society. While these surveys help to identify potential barriers to full participation in society, they reveal little information on the individual's needs and desires towards active ageing. Do they indeed desire a higher level of participation, or do they rather participate in different ways? Do they really experience the potential barriers identified in survey research as limiting their choice options, and how do they negotiate these barriers in order to overcome them? Given the centrality of agency for inclusion, we should not only have information on what we as researchers consider structural barriers, but also on whether older individuals perceive them as such: we can only really talk about exclusion if we can identify a loss of agency. Hence, this is a plea to go beyond describing older people's actions, bodies and environments in surveys for the older population, and to also include questions on identities and life goals, opinions and reasons for their actions. Until then, survey research is prone to picturing older individuals as passive victims of their circumstances, rather than as active agents pursuing their own goals and trying to overcome obstacles on the way. The qualitative literature in the field is leading the way.

\section{Acknowledgments}

This thematic issue was made possible with the support of COST Actions CA15122 "ROSEnet-Reducing Old-Age Social Exclusion: Collaborations in Research and Policy" (www.rosenetcost.com) and IS1402 "Ageism-A Multi-National, Interdisciplinary Perspective" (www.notoageism.com).

\section{Conflict of Interests}

The authors declare no conflict of interests.

\section{References}

Ayalon, L., \& Tesch-Römer, C. (2017). Taking a closer look at ageism: Self- and other-directed ageist attitudes and discrimination. European Journal of Ageing, 14(1), 1-4.

Ayalon, L., \& Tesch-Römer, C. (Eds.). (2018). Contemporary perspectives on ageism. Berlin: Springer.

Boudiny, K. (2013). "Active ageing”: From empty rhetoric to effective policy tool. Ageing \& Society, 33(6), 1077-1098.

Butler, R. N. (1969). Age-ism: Another form of bigotry. The Gerontologist, 9(4), 243-246.

De Tavernier, W. (2016). The family as provider of welfare: The role of gender and the family in welfare opinions, preferences, actions and outcomes. Aal- 
borg: Aalborg University Press.

De Tavernier, W., \& Draulans, V. (2019). Negotiating informal elder care, migration and exclusion: The case of a Turkish immigrant community in Belgium. International Journal of Ageing and Later Life, 12(2), 89-117.

De Tavernier, W., Naegele, L., \& Hess, M. (2019). A critical perspective on ageism and modernization theory. Social Inclusion, 7(3), 54-57.

De Tavernier, W., \& Roots, A. (2015). When do people want to retire? The preferred retirement age gap between Eastern and Western Europe explained. Studies of Transition States and Societies, 7(3), 7-20.

European Commission. (2018). Active ageing. Europa. Retrieved from ec.europa.eu/social/main.jsp?catld= 1062\&langld=ent

Foster, L., \& Walker, A. (2015). Active and successful aging: A European policy perspective. The Gerontologist, 55(1), 83-90.

Hess, M. (2016). Rising preferred retirement age in Europe: Are Europe's future pensioners adapting to pension system reforms? Journal of Aging \& Social Policy, 29(3), 245-261.

Jensen, P. H., Kongshøj, K., \& De Tavernier, W. (2018). On how the nature of early retirement is related to postretirement life conditions from a citizenship perspective. Ageing \& Society. Advance online publication. https://doi.org/10.1017/S0144686X18001691

Marshall, T. H. (1950). Citizenship and social class and other essays. Cambridge: Cambridge University Press.

Peeters, H., \& De Tavernier, W. (2015). Lifecourses, pensions and poverty among elderly women in Belgium: interactions between family history, work history and pension regulations. Ageing \& Society, 35(6), 1171-1199.

Pfaller, L., \& Schweda, M. (2019). Excluded from the good life? An ethical approach to conceptions of active ageing. Social Inclusion, 7(3), 44-53.

Precupetu, I., Aartsen, M., \& Vasile, M. (2019). Social exclusion and mental wellbeing in older Romanians. Social Inclusion, 7(3), 4-16.

Preston, C. (2019). What are the structural barriers to planning for later life? A scoping review of the literature. Social Inclusion, 7(3), 17-26.

Swift, H., Abrams, D., Lamont, R. A., \& Drury, L. (2017). The risks of ageism model: How ageism and negative attitudes towards age can be a barrier to active aging. Social Issues and Policy Review, 11(1), 195-231.

United Nations. (2002). Political declaration and Madrid international plan of action on ageing. New York, NY: United Nations.

Van der Horst, M. (2019). Internalised ageism and selfexclusion: Does feeling old and health pessimism make individuals want to retire early? Social Inclusion, 7(3), 27-43.

Walker, A. (2008). Commentary: The emergence and application of active aging in Europe. Journal of Aging \& Social Policy, 21(1), 75-93.

Walsh, K., Scharf, T., \& Keating, N. (2017). Social exclusion of older persons: A scoping review and conceptual framework. European Journal of Ageing, 14(1), 81-98.

World Health Organization. (2002). Active ageing: A policy framework. Geneva: World Health Organization.

\section{About the Authors}

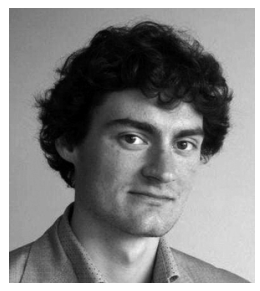

Wouter De Tavernier is a Postdoc Researcher at the Center for Social and Cultural Psychology, KU Leuven (Belgium). His research interests include employment of older workers, retirement, pensions and ageism. Before, he worked as a researcher at the Centre for Comparative Welfare Studies, Aalborg University (Denmark) where he also obtained his PhD, and at the Center for Sociological Research, KU Leuven.

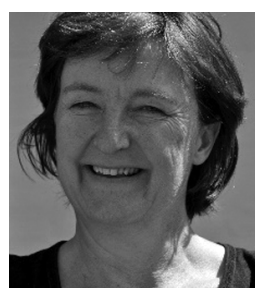

Marja Aartsen is Research Professor at OsloMet-Oslo Metropolitan University, Norway. Her research is on longitudinal developments in older adults' social network, social participation and loneliness in relation to cognitive, physical, and mental health. Her work includes aspects of social exclusion and the role of the local and national context. She is involved in the European research collaboration on social exclusion in older adults (GENPATH), and co-leader of a working group on exclusion from social relations of the COST Action ROSENET, and editor of the European Journal of Ageing. 